\title{
ARTICLE
}

\section{East London deliberate corrosive fluid injuries}

\author{
Ruhella R. Hossain ${ }^{1}$ Esther Papamichael ${ }^{1}$ Andrew Coombes ${ }^{1}$
}

Received: 12 January 2019 / Revised: 29 April 2019 / Accepted: 22 August 2019 / Published online: 25 September 2019

(c) The Author(s), under exclusive licence to The Royal College of Ophthalmologists 2019

\begin{abstract}
Objectives The aims of this case series are to (1) highlight the incidence of deliberate corrosive fluid injuries (DCFI) in East London; (2) ascertain the types of substances used; and (3) grade the resulting ocular surface burns using two validated grading systems.

Methods The Metropolitan Police 2017 Freedom of Information (FOI) requests were reviewed for DCFI. We retrospectively reviewed patient records between October 2016 and 2017 from local A\&E departments for DCFI. Roper-Hall and Dua Classifications were used to classify prognoses in patients with deliberate ocular corrosive fluid injuries (DOCFI).

Results The FOIs demonstrated an increasing trend with the highest number of DCFI surrounding our centre. We identified 57 patients with DCFI. Based on pre-irrigation $\mathrm{pH}$ measurement, $54.4 \%(n=31)$ sustained acidic; $21.1 \%(n=12)$ alkaline and 24.6\% $(n=14)$ unknown injuries. More than half, 66.7\% $(n=38)$, sustained DOCFI with median presentation visual acuity (VA) $0.25 \operatorname{LogMAR}(n=26$, IQR: $0.10-0.39)$ and 1 month VA $0.20 \operatorname{LogMAR}(n=16$, IQR: $0.02-0.20)$. Prognosis of the worse eye using (1) Roper-Hall Classification was 55\% good (Grade I-II); 23\% guarded (Grade III); 23\% guarded (Grade IV); and (2) Dua Classification was 23\% very good (Grade I); 35\% good (Grade II-III); 19\% good to guarded (Grade IV); $23 \%$ guarded to poor (Grade V); and $0 \%$ very poor (Grade VI).

Conclusions DCFI mostly affected young men in this cohort. Our clinical experience suggested an alarming increase in DCFI and is supported by police data. Although this patient group appears to show relatively good outcomes, legislation to prevent these attacks should be prioritised.
\end{abstract}

\section{Introduction}

In the past two years several high-profile cases highlighted the increase in deliberate corrosive fluid injuries (DCFI) in London. These injuries caused debilitating, life-changing or life-threatening injuries to the face, body, and eyes. Patients report being accosted in public by a stranger and deliberately sprayed in the face and eyes with unknown corrosive substances, of varying $\mathrm{pH}$. These DCFI cause physical and psychological harm, with recovery dependent upon the extent of the initial damage [1]. Validated grading systems for ocular surface burns exist, including Roper-Hall (modified Hughes) and Dua Classification Systems that allow for stratification of severity, visual prognosis, and management.

Ruhella R. Hossain

ruhella.hossain@gmail.com

1 Department of Ophthalmology, The Royal London Hospital, Barts Health NHS Trust, Whitechapel Road, London E1 1BB, UK
Roper-Hall is based on the degree of corneal involvement and peri-limbal ischaemia [2,3]. Dua estimates the extent of bulbar conjunctival and limbal involvement and translates into an analogue scale [4].

In 2017 the media reported an increase of DCFI compared with previous years. In the wake of these attacks, the general public called for government action to combat this public health issue, including limiting the sale of corrosive substances to individuals less than 18 years old. According to a House of Commons publication, these calls for change focused on: (1) restricting the sale of corrosive substances to the public; (2) new criminal offences relating to the possession of corrosive substances; and (3) sentencing [5].

Our hospital, a major trauma centre near central London, receives patients with suspected DCFI affecting the face, body, and eyes. The aims of this retrospective case series are to (1) highlight the incidence of DCFI in East London; (2) ascertain the types of substances used in these assaults; and (3) grade ocular surface burns using two validated grading systems. 


\section{Methods}

Metropolitan Police Freedom of Information (FOI) requests were reviewed for attacks with corrosive substances particularly in East London. The FOI extracted data on 4th May 2017 and focused on offences "causing explosions, sending explosive substance or throwing corrosive fluids with intent to do grievous bodily harm" or Total Notifiable Offences criminal records with the feature code $\mathrm{CB}$-noxious or corrosive gas used e.g. acid thrown between 1st January 2010 and 28th February 2017 [6, 7].

We conducted a retrospective case series from October 2016 to 2017 for patients with suspected DCFI presenting either to The Royal London Hospital or Homerton University Hospital Accident \& Emergency (A\&E), two busy East London hospitals near central London. Hospital electronic records were reviewed for patients reporting DCFI or burns with or without other injuries and requiring Ophthalmology review. Where available, we collected data on patient demographics, location of attacks, $\mathrm{pH}$ on arrival to $A \& E$, extent of ocular surface burn, prescribed medication, and visual acuity (VA) in the worse affected eye both at the time of injury and one month post-injury. Conjunctival sac $\mathrm{pH}$ was measured using universal litmus paper. Prognosis of the worse eye was classified using two validated grading systems, Roper-Hall and Dua Classifications. Classification was graded according to description of the extent of injury documented by the first Ophthalmologist to examine the patient.

Non parametric tests were used as our data was not normally distributed. Research \& Ethics Committee approval was not required for this retrospective review.

\section{Results}

The Metropolitan Police FOI reports extracted data on 4th May 2017 for records matching the offence described above $[6,7]$. The number of offences by each London borough, as reported by the Metropolitan Police FOI reports, is shown in Table 1.

We identified 57 patients who attended our hospitals with suspected DCFI with or without ocular involvement during our study period. Post-code prefix location of attacks were identified ( $n=49,8$ not documented) and superimposed on an East London map showing total crime rates for the same period (Fig. 1) [8]. Of these patients, the majority were male $(93 \%, n=53)$; the median age was 23 (IQR: 19.8-28) and varying ethnicities (Table 2).

Our group identified 57 patients with DCFI with and without DOCFI. Based on pre-irrigation $\mathrm{pH}$ measurement of the skin and eyes $54.4 \%(n=31)$ sustained acidic injuries; $21.1 \%(n=12)$ had alkaline injuries and $24.6 \%$
Table 1 Data from Metropolitan Police Freedom of Information

\begin{tabular}{|c|c|c|c|c|c|c|c|}
\hline Borough & 2010 & 2011 & 2012 & 2013 & 2014 & 2015 & 2016 \\
\hline $\begin{array}{l}\text { Barking and } \\
\text { Dagenham }^{\mathrm{a}}\end{array}$ & 17 & 13 & - & 15 & 15 & 29 & 58 \\
\hline Barnet & 12 & 12 & 10 & - & 7 & - & 10 \\
\hline Bexley & - & - & - & - & - & - & - \\
\hline Brent & - & 9 & - & - & - & - & 7 \\
\hline Bromley & 14 & - & 6 & - & - & - & - \\
\hline Camden & - & - & - & 9 & - & - & - \\
\hline Croydon & 10 & 11 & 13 & 10 & - & - & - \\
\hline Ealing & 8 & 12 & 13 & 7 & - & - & - \\
\hline Enfield & - & - & - & - & - & 7 & - \\
\hline Greenwich & 6 & 9 & - & - & - & - & 9 \\
\hline Hackney $^{\mathrm{a}}$ & 9 & 0 & - & - & - & 15 & 21 \\
\hline $\begin{array}{l}\text { Hammersmith } \\
\text { and Fulham }\end{array}$ & - & 9 & 6 & 7 & - & - & - \\
\hline Haringey & 7 & - & - & - & 6 & - & 6 \\
\hline Harrow & - & 8 & - & 6 & - & - & - \\
\hline${ }^{\mathrm{a}}$ Havering & 26 & 27 & 8 & 9 & 6 & 7 & 25 \\
\hline Hillingdon & 11 & 11 & 6 & 8 & - & - & - \\
\hline Hounslow & 15 & 9 & 6 & - & - & - & 7 \\
\hline Islington & 11 & 10 & - & 0 & - & 8 & 9 \\
\hline $\begin{array}{l}\text { Kensington and } \\
\text { Chelsea }\end{array}$ & - & - & - & - & - & - & - \\
\hline $\begin{array}{l}\text { Kingston } \\
\text { upon Thames }\end{array}$ & 9 & - & - & 0 & 0 & - & 8 \\
\hline Lambeth & 9 & 0 & - & - & - & - & 6 \\
\hline Lewisham & 8 & 12 & - & - & - & - & 7 \\
\hline Merton & 6 & - & - & 7 & - & - & - \\
\hline Newham $^{a}$ & 13 & 27 & 21 & 71 & 54 & 76 & 149 \\
\hline Redbridge $^{\mathrm{a}}$ & - & - & 6 & - & 11 & 26 & 27 \\
\hline $\begin{array}{l}\text { Richmond } \\
\text { upon Thames }\end{array}$ & - & 11 & - & - & - & - & - \\
\hline Southwark & 8 & 7 & - & - & - & - & - \\
\hline Sutton & 25 & 9 & - & - & - & 6 & 0 \\
\hline Tower Hamlets ${ }^{\mathrm{a}}$ & - & 7 & - & - & 6 & 24 & 42 \\
\hline Waltham Forest ${ }^{\mathrm{a}}$ & 10 & - & - & - & - & - & 15 \\
\hline Wandsworth & - & - & - & - & - & - & - \\
\hline Westminster & 14 & 9 & - & - & - & - & - \\
\hline Grand total & 293 & 259 & 162 & 210 & 166 & 261 & 454 \\
\hline
\end{tabular}

Reported number of offences from 1 January 2010 to 31 December 2016 "causing explosions, sending explosive substances or throwing corrosive fluids with intent to do grievous bodily harm" or Total Notifiable Offences criminal records with the feature code $\mathrm{CB}$-noxious or corrosive gas used e.g. acid thrown [6]

${ }^{\mathrm{a}}$ Boroughs covered by our unit and included in this study

$(n=14)$ of unknown type due to lack of documentation. More than half, $66.7 \% \quad(n=38)$, sustained suspected deliberate ocular corrosive fluid injuries (DOCFI). Six of these patients were transferred to regional burns units due to other injuries and one did not attend the scheduled clinic 
A)

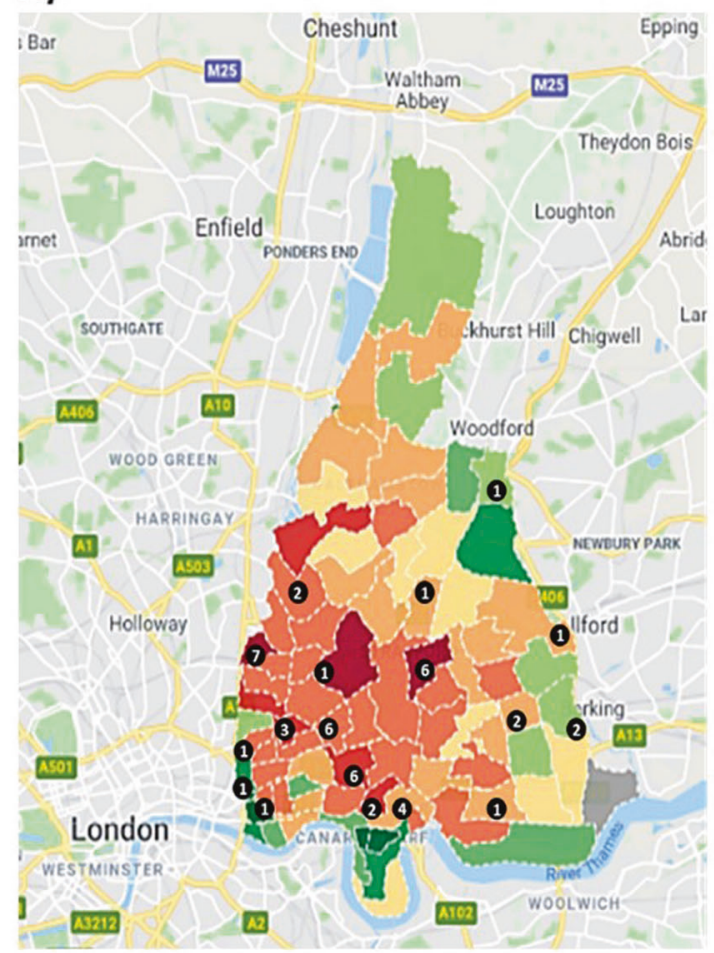

B)

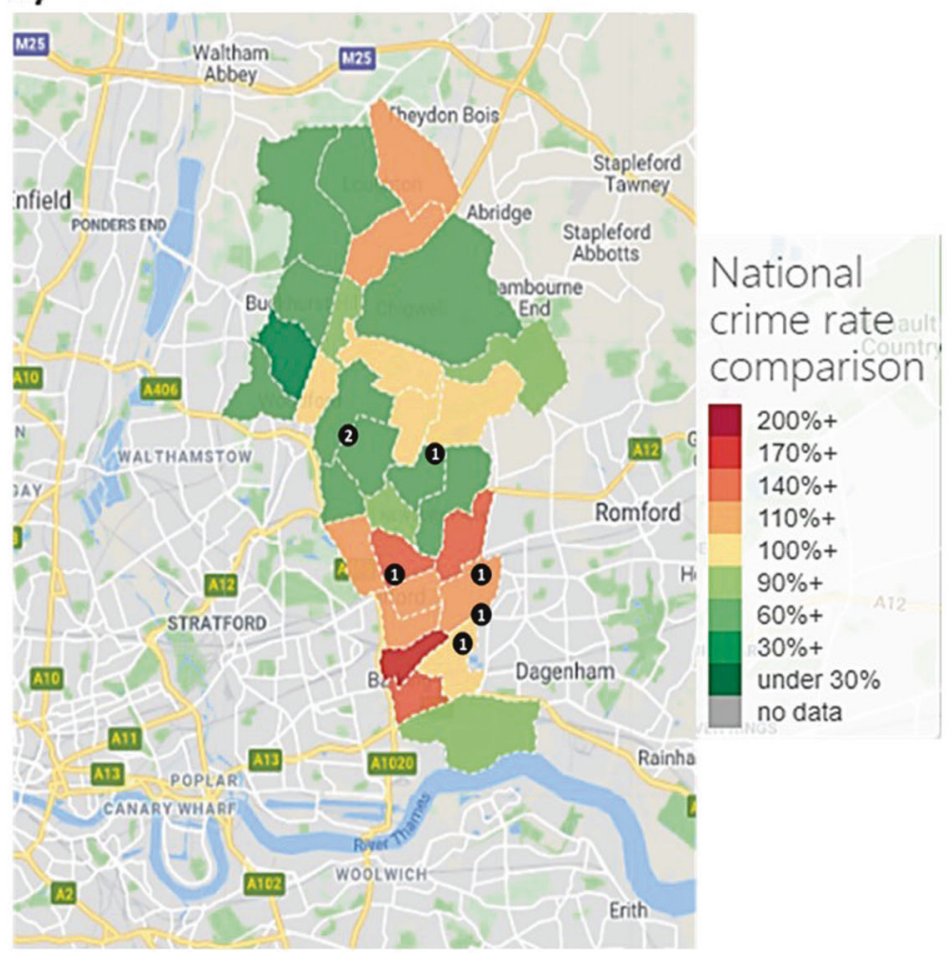

Fig. 1 Number of deliberate ocular chemical injuries identified during our study period per post-code superimposed on a map indicating East London districts a Tower Hamlets and Stratford and b Ilford and Barking crime rates in 2017 [8]

Table 2 Ethnicities of patients included in the study

\begin{tabular}{lll}
\hline Ethnicity & $n$ & $\%$ \\
\hline White & 9 & \\
$\quad$ White British & 2 & 15.8 \\
$\quad$ Other White background & 2 & 3.5 \\
White and Black Caribbean & & 3.5 \\
Asian/Asian British & 10 & \\
$\quad$ Bangladeshi & 1 & 17.5 \\
$\quad$ Pakistani & 1 & 1.8 \\
$\quad$ Chinese & & 1.8 \\
Black/African/Caribbean & 4 & 7 \\
$\quad$ Black African & 1 & 1.8 \\
$\quad$ Other Black & 9 & 15.8 \\
Other & 18 & 31.6 \\
Not stated & 57 & \\
Total &
\end{tabular}

appointment. Of the remaining 31 patients, $61.3 \%(n=19)$ of the patients suffered bilateral DOCFI.

We analysed VA data in groups according to initial $\mathrm{pH}$ recordings; those with acidic burns, alkaline burns, and unknown $\mathrm{pH}$ burns. In the group of patients attacked with acidic substances the median VA was 0.20 LogMAR (IQR: $0.10-0.38)$ at presentation $(n=15)$ and $0.20 \operatorname{LogMAR}$
(IQR: $0.00-0.30)$ at one month $(n=10)$. In the group that suffered alkaline burns the median VA was 0.40 LogMAR (IQR: $0.25-0.76)$ at presentation $(n=7)$ and $0.10 \operatorname{LogMAR}$ (IQR: 0.06-0.18) at one month $(n=8)$. In the unknown $\mathrm{pH}$ group the median VA was 0.30 LogMAR (IQR: 0.00-0.36) at presentation $(n=5)$ and no VA data was available at one month due to loss of follow-up. In the DOCFI group, the median VA at presentation was $0.25 \operatorname{LogMAR}(n=26$, IQR: $0.10-0.39)$ and at one month $0.20 \operatorname{LogMAR}(n=16$, IQR: 0.02-0.20). The Roper-Hall and Dua Classification gradings and prognoses are shown in Table $3 \mathrm{a}, \mathrm{b}$ and photographs of one patient with severe chemical injuries are shown in Fig. 2.

The medical and surgical management of our patients is summarised in Table 4. Choice of treatment was based on local guidelines, which took into account the patients' presenting injury severity.

\section{Discussion}

In 2017 the media reported an increased number of "acid attacks" or deliberate chemical attacks with unknown corrosive substances. Limited empirical literature exists examining DCFI with or without ophthalmic involvement. In 1990, Beare et al. reported on 64 patients with 
Table 3 Deliberate ocular chemical injuries severity of the worse affected eye using a) Roper-Hall and b) Dua Classification Grading Systems

\begin{tabular}{|c|c|c|c|c|c|c|c|c|c|}
\hline \multirow[b]{2}{*}{ Grade } & \multirow[b]{2}{*}{ Prognosis } & \multicolumn{2}{|c|}{ Acidic $(n=17)$} & \multicolumn{2}{|c|}{ Alkaline $(n=9)$} & \multicolumn{2}{|c|}{ Unknown $(n=5)$} & \multicolumn{2}{|c|}{ Total $(n=31)$} \\
\hline & & $n$ & $\%$ & $n$ & $\%$ & $n$ & $\%$ & $n$ & $\%$ \\
\hline \multicolumn{10}{|c|}{ Roper-Hall } \\
\hline $\mathrm{I}-\mathrm{II}$ & Good & 9 & 29 & 5 & 16 & 3 & 10 & 17 & 55 \\
\hline III & Guarded & 4 & 13 & 2 & 6 & 1 & 3 & 7 & 23 \\
\hline IV & Poor & 4 & 13 & 2 & 6 & 1 & 3 & 7 & 23 \\
\hline \multicolumn{10}{|l|}{ Dua } \\
\hline I & Very good & 3 & 10 & 1 & 3 & 3 & 10 & 7 & 23 \\
\hline II-III & Good & 6 & 19 & 5 & 16 & 0 & 0 & 11 & 35 \\
\hline IV & Good to guarded & 3 & 10 & 1 & 3 & 2 & 6 & 6 & 19 \\
\hline $\mathrm{V}$ & Guarded to poor & 5 & 16 & 2 & 6 & 0 & 0 & 7 & 23 \\
\hline VI & Very poor & 0 & 0 & 0 & 0 & 0 & 0 & 0 & 0 \\
\hline
\end{tabular}

Severity sub-classified according to initial $\mathrm{pH}$ documented on arrival to A\&E post-injury

Fig. 2 Photographs of patient with Roper-Hall Grade IV and Dua Grade V chemical injury to his right eye, looking in different directions. The patient's initial VA was counting fingers and post-amniotic membrane graft VA was $0.20 \log$ MAR
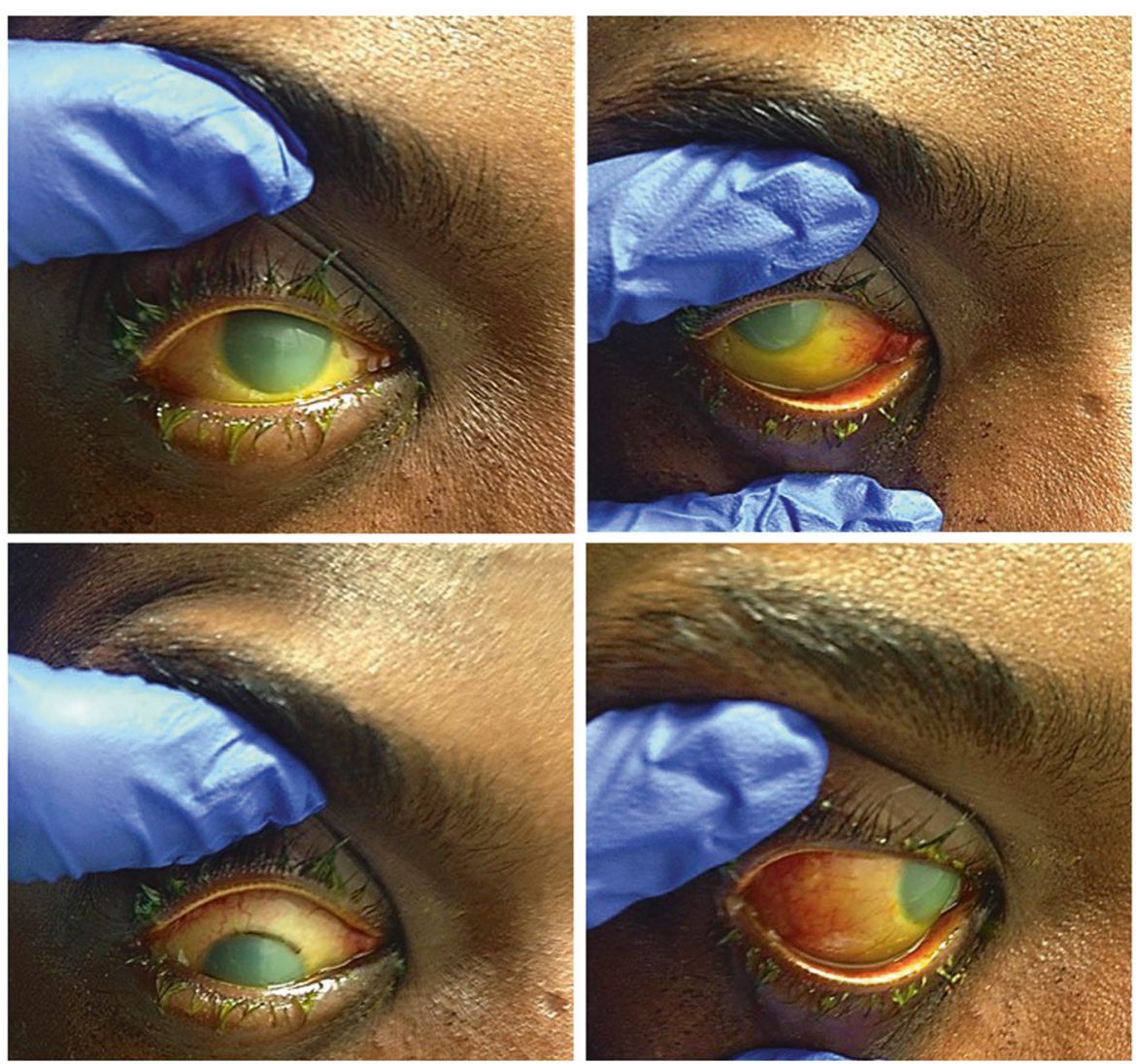

ophthalmic injuries secondary to chemical assaults in West London [9]. In 2015, Tan et al. identified 21 patients over a 15 year period presenting with chemical burns from assaults to one of the largest regional burn centres in the UK [10]. We found 57 patients in one year presenting to two East London hospitals who sustained suspected DCFI. Motivations for these acts were unknown. All of the patients were assaulted outside of their homes with some reporting being accosted by a stranger after leaving a night club or a football match, or having unknown substances thrown into their open car window. Metropolitan Police FOIs supported this increased trend in London. The highest number of offences occurred in East London in the boroughs surrounding The Royal London and Homerton University Hospitals. Although 2017 data from the Metropolitan Police was not published in the FOI, our case series shows an ongoing 
Table 4 Medical and surgical management of patients included in our cohort

\begin{tabular}{|c|c|c|c|c|c|c|c|c|}
\hline \multirow[t]{2}{*}{ Medication } & \multicolumn{2}{|c|}{ Acidic $(n=17)$} & \multicolumn{2}{|c|}{ Alkaline $(n=9)$} & \multicolumn{2}{|c|}{ Unknown $(n=5)$} & \multicolumn{2}{|c|}{ Total $(n=31)$} \\
\hline & $n$ & $\%$ & $n$ & $\%$ & $n$ & $\%$ & $n$ & $\%$ \\
\hline Chloramphenicol drops & 17 & 100 & 9 & 100 & 5 & 100 & 31 & 100 \\
\hline Artificial tear drops & 12 & 67 & 9 & 90 & 3 & 60 & 24 & 73 \\
\hline Cycloplegic drops & 11 & 61 & 6 & 60 & 2 & 40 & 19 & 58 \\
\hline Steroid drops & 16 & 89 & 10 & 100 & 2 & 40 & 28 & 85 \\
\hline Vitamin $\mathrm{C}$ tablets & 12 & 67 & 9 & 90 & 0 & 0 & 21 & 64 \\
\hline Doxycycline tablets & 11 & 61 & 7 & 70 & 2 & 40 & 20 & 61 \\
\hline Ascorbate drops & 4 & 22 & 5 & 50 & 1 & 20 & 10 & 30 \\
\hline Amniotic membrane graft & 0 & 0 & 1 & 10 & 0 & 0 & 1 & 3 \\
\hline Bandage contact lens & 1 & 6 & 2 & 20 & 0 & 0 & 3 & 9 \\
\hline
\end{tabular}

number of offences with higher number of assaults occurring in high-crime rate areas in comparison with the national average for that time period.

The high incidence of DCFI presents a challenge to clinicians and law enforcement. Victims of these offences provided support to public petitions calling for action and arguing that corrosive substances are used as weapons to threaten or attack people and inflict life-changing injuries. In January 2018, the UK Government proposed method to address this increased and seemingly targeted trend included companies voluntarily limiting the sale and delivery of corrosive substances to under 18 year olds and no specific criminal offence for possessing certain corrosive substances in a public space "without good reason" [11, 12]. Public consultations argued that these measures were inadequate to address this public health issue. On 20 June 2018, the UK Government introduced The Offensive Weapons Bill 2017-19 and debated the remaining stages on 28 November 2018. Although this Bill covers acids, knives and offensive weapons, and firearms, only the former is within the remit of this study. The Bill creates new restrictions on the sale and delivery of corrosive substances to under 18 year olds; a new offence for possessing corrosive substances in public; and provides the police with stop and search powers relating to corrosive substances. The Bill was introduced to the House of Lords on 29 November 2018 with a second reading and general debate on 7 January 2019 [13].

In our case series, $93 \%$ of those affected were young males and two-thirds of the patients presenting with suspected attacks by a corrosive substance sustained DOCFI. For those with known ethnicity, there were a high number of White and Bangladeshi patients. This is not to suggest an ethnic cause but rather the demographics of East London. After the injury patients worry about visual outcomes and the likelihood of permanent loss of vision. The severity of damage to the ocular surface depends on the substances used, duration of exposure, depth of penetration, and area of involvement. Thus, the priority of early management post-
DOCFI is irrigation to remove the caustic agent and restore normal $\mathrm{pH}$. Incomplete documentation of pre-irrigation $\mathrm{pH}$ prevented us from determining if these were acid or alkali attacks. Irrigation either dilutes or removes the caustic agent, thus skewing our $\mathrm{pH}$ results towards acidic values.

Irrigation solution type was not documented in the patient medical records. Our information suggests that prior to receiving medical assistance, patients used tap or bottled water immediately after injury due to its wide availability. Herr et al. performed a prospective, double-blind study comparing the different irrigation fluids, including normal saline, normal saline with bicarbonate, Ringer's lactate solution, balanced salt solution (BSS), and BSS Plus [14]. They report that all solutions had comparable normalisation of $\mathrm{pH}$ and that patients preferred BSS Plus solution over the other solutions. Twenty-six years later Alexander et al. reported improved outcomes using Diphoterine irrigating solution, including reduced tissue necrosis and severity of symptoms, faster $\mathrm{pH}$ resolution, and reduction in pain [15]. In the future we expect to see increased use of Diphoterine irrigation solution.

Further management post-DOCFI depends on the severity and grade of the ocular chemical burn. The retrospective review of our patient cohort medical records showed that overall visual outcomes were good as most patients sustained injuries of either very good, good, or guarded prognosis. A minority of patients had injuries which were classified as having a poor prognosis with an overall median VA 0.25 LogMAR at presentation and 0.20 LogMAR after one month. Median VA in the alkaline group was worse at initial presentation and better at one month compared with the acidic group. None of the patients with ocular injuries had very poor prognosis. However, a proportion of patients presenting to our casualty department were transferred to neighbouring units due the severity of their non-ocular injuries. This selection bias may have positively skewed our results. 
Medical management regimens usually consist of topical prophylactic antibiotic, steroid, cycloplegic agent, artificial tears, ascorbate, and oral ascorbic acid. In our cohort, only one patient required surgical treatment for his injuries. Sodium citrate, although shown to inhibit polymorphonuclear cells and proteases after severe chemical injuries, was not prescribed [16]. This review has highlighted the local lack of availability and we are updating our local guidelines to incorporate both ascorbate and citrate.

Careful examination and grading of DOCFI enabled better stratification of severity which allowed for appropriate stratification of treatment and intensity of follow-up. The ocular chemical burns were graded using two validated grading systems using descriptions documented by the first ophthalmologist to examine the patient. However, recent studies show the subjective nature of clinical assessment and lack of agreement regarding limbal ischaemia, even among corneal specialists [17, 18]. Non-invasive optical coherence tomography angiography of the anterior segment may help to define accurately the location and extent of limbal ischaemia [19].

In conclusion, our cohort demonstrated that DCFI mostly affected young men; and careful examination and grading of DOCFI to enable better stratification of prognosis is important. Our clinical experience has suggested an alarming increase in DCFI with and without ocular involvement in East London and this increase has been supported by data obtained from the Metropolitan Police. Although our patient group appears to show relatively good outcomes, legislative action by the government to prevent these attacks should be prioritised.

\section{Summary}

\section{What was known before}

- In the past two years several high-profile cases highlighted the increase in deliberate corrosive fluid injuries (DCFI) in London, causing debilitating, life changing or life threatening injuries to the face, body, and eyes.

- Limited empirical literature exists examining deliberate corrosive fluid injuries with or without ophthalmic involvement.

- The general public called for increased government legislation to combat this public health issue.

\section{What this study adds}

- Our clinical experience has suggested an alarming increase in DCFI in East London and is supported by the Metropolitan Police data, with the highest number of offences in the boroughs surrounding our centre.
- Our cohort demonstrated that DCFI mostly affected young men; and careful examination and grading of deliberate ocular corrosive fluid injuries to enable better stratification of prognosis is important.

\section{Compliance with ethical standards}

Conflict of interest The authors declare that they have no conflict of interest.

Publisher's note Springer Nature remains neutral with regard to jurisdictional claims in published maps and institutional affiliations.

\section{References}

1. Ballen PH. Treatment of chemical burns of the eye. Eye Ear Nose Throat Mon. 1964;43:57-61.

2. Hughes W. Alkali burns of the eye. I. Review of the literature and summary of present knowledge. Arch Ophthalmol. 1946;35:423.

3. Roper-Hall MJ. Thermal and chemical burns. Trans Ophthalmol Soc UK. 1965;85:631-53.

4. Dua HS, King AJ, Joseph A. A new classification of ocular surface burns. Br J Ophthalmol. 2001;85:1379-83.

5. Hutton S, Lipscombe G. Acid attacks. Briefing paper: number CBP 8041, 17 December 2017. London: House of Commons Library. https://researchbriefings.parliament.uk/ResearchBriefing/ Summary/CBP-8041\#fullreport.

6. Metropolitan Police. Information Rights Unit-Violent crimes involving corrosive substances broken down from 2010 to February 2017. Metropolitan Police. 2017. https://www.met.police. uk/SysSiteAssets/foi-media/metropolitan-police/disclosure_ 2017/april_2017/information-rights-unit--violent-crimesinvolving-corrosive-substances-broken-down-from-2010-tofebruary-2017.

7. Metropolitan Police. Information Rights Unit-Acid attacks in the London area from January 2014 to April 2017. Metropolitan Police. 2017. https://www.met.police.uk/SysSiteAssets/foi-media/ metropolitan-police/disclosure_2017/july_2017/informationrights-unit---acid-attacks-in-the-londonarea-from-january-2014to-april-2017.

8. PlumPlot. PlumPlot crime statistics. PlumPlot; 2017. https://www. plumplot.co.uk/East-London-violent-crime-statistics.html.

9. Beare JD. Eye injuries from assault with chemicals. Br J Ophthalmol. 1990;74:514-8.

10. Tan A, Bhark AK, Nizamoglu M, Barnes D, Dzlewulski P. Assaults from corrosive substances and medico legal considerations in a large regional burn centre in the United Kingdom: calls for increased vigilance and enforced legislation. Scars, Burns \& Healing. 2015;1. https://doi.org/10.1177/ 2059513115612945.

11. United Kingdom Home Office. Policy paper: Responsible sales of acid and corrosive substances: voluntary commitments. Gov.UK. 25 July 2018. https://www.gov.uk/government/publica tions/sales-of-acid-voluntary-commitments-for-retailers/ responsible-sales-of-acid-and-corrosive-substances-voluntarycommitments.

12. Lipscombe S, Brown J, Allen G. The offensive weapons bill 2017-19. Briefing paper: number 08349, 11 October 2018.

13. House of Lords Library. Offensive weapons bills: briefing for lords stages. 18 December 2018. https://researchbriefings.parlia ment.uk/ResearchBriefing/Summary/LLN-2018-0143, 
14. Herr RD, White GL, Bernhisel K, Mamalis N, Swanson E. Clinical comparison of ocular irrigation fluids following chemical injury. Am J Emerg Med. 1991;9:228-31.

15. Alexander KS, Wasiak J, Cleland H. Chemical burns: Diphoterine untangled. Burns. 2017;:S0305-4179:30506-5.

16. Paterson CA, Williams RN, Parker AV. Characteristics of polymorphonuclear leukocyte infiltration into the alkali burned eye and the influence of sodium citrate. Exp Eye Res. 1984;39:701-8
17. Oie Y, Nishida K. Evaluation of corneal neovascularization using optical coherence tomography angiography in patients with limbal stem cell deficiency. Cornea. 2017;36:S72-5.

18. Kam KW, Patel CN, Nikpoor N, Yu M, Basu S. Limbal ischemia: reliability of clinical assessment and implications in the management of ocular burns. Indian J Ophthalmol. 2019;67:32-6.

19. Ang M, Sim DA, Keane PA, Sng CCA, Egan CA, Tufail A, et al. Optical coherence tomography for anterior segment vasculature imaging. Ophthalmology. 2015;112:1740-7. 